\title{
Inter mensas et pocula: comensalismo y alimentación como paradigmas alógenos y su tratamiento en la historiografía de Prisco de Panion (siglo V)
}

Silvia Acerbi

\section{Universidad de Cantabria*}

silvia.acerbi@unican.es

\section{Fecha recepción: 14.10.2020 / Fecha aceptación: 06.05.2021}

\section{Resumen}

En el presente artículo nos proponemos analizar, en el contexto de la obra historiográfica de Prisco de Panion, los fragmentos relativos a una expedición realizada en el 449 por los delegados del emperador Teodosio II en el campamiento de Atila. En particular nos ocuparemos del Fr. 8, un singular relato autóptico que se tiñe del carácter

\begin{abstract}
In this article we propose to analyze, in the context of the historiographic work of Priscus of Panion, the fragments relating to an expedition carried out in 449 by the delegates of the emperor Theodosius II at Attila's camp. In particular, we will deal with Fr. 8, a singular autoptical story that is tinged with the hybrid and polymorphic character of the odei-
\end{abstract}

*Este trabajo se enmarca en el Proyecto de Investigación MCIU/AEI/FEDER,UE titulado "Heterotopías de la autoridad y de la sacralidad en el Mediterráneo cristiano tardo-antiguo, siglos IV-VI) (PGC2018-099798-B-I00). 
híbrido y polimorfo del género odeipórico y en el que se sedimenta la experiencia del encuentro con "los Otros". A este propósito focalizaremos nuestra atención en el tema de la alimentación y del banquete como marcadores histórico-antropológicos de alteridad.

Nuestro objetivo es demostrar que las costumbres convivales adoptadas por los Hunos, más que variaciones de praxis en uso en otros pueblos esteparios, como se ha escrito hasta fechas recientes, parecen ser una imitación de los usos de la mesa en la corte imperial oriental. Nuestra lectura de las fuentes viene en parte a confirmar la interpretación de la historiografía actual que, superando una visión anclada en una total alteridad de los Hunos con respecto a los romaioi, defiende relaciones abiertas y fluidas en el contexto de inevitables procesos de asimilación.

\section{Palabras clave}

Comensalismo, alimentación, historiografía, tardoantigua, Prisco de Panion, Hunos poric genus and in which the experience of the encounter with "the Others" is embedded. In this regard, we will focus our attention on the theme of food and the banquet as historical-anthropological markers of otherness. Our aim is to show that the convivial customs adopted by the Huns, rather than variations of practices in use in other steppe peoples - as has been written until recently - seem to be an imitation of the uses of the table at the Eastern imperial court. Our interpretation of the sources partially confirms the interpretation of current historiography which, overcoming a vision anchored in a total otherness of the Huns vis-à-vis the Romans (i.e., the Byzantines), defends open and fluid relations in the context of inevitable processes of assimilation.

\section{Keywords}

Commensalism, food, Late-Antique Historiography, Priscus of Panion, Huns 
Ah! Tout est bu! Bathylle, as-tu fini de rire? Ah! Tout est bu, tout est mangé! Plus rien à dire!

P. Verlaine, Langueur

Vagué por estepas que conservan en su memoria el alarido de los Hunos... J. A. Brodsky, Estuve en una jaula

En Mármoles, obra dialógica escrita por el Nobel de Literatura en el año 1987, Josif Aleksandrovič Brodsky, Tulio, un romano auténtico, orgulloso de su cultura y refinamiento, y Publio, un ex soldado bárbaro de gustos y apetitos vastos, comparten el espacio angosto de una celda. El diálogo se sucede rápido, marcado por las sarcásticas afirmaciones del romano que insistentemente se dirige a su interlocutor refrendando con arrogancia su incapacidad de entender: «Pero TÚ eres un bárbaro ${ }^{1} »$.

Las representaciones de la identidad siempre se han expresado mediante la dicotomía entre el yo y el otro, opuestos complementarios pero irreconciliables de una construcción cultural donde el yo generalmente se caracteriza por la sobrevaloración propia unida a la denigración del otro. La mirada hacia los pueblos definidos «bárbaros» ha manifestado el punto de vista autoreferencial de individuos o colectividades hacia una otherness concebida no sólo como inferior sino también como usurpadora ${ }^{2}$, revelando hasta qué punto, en la compleja dialéctica entre aceptación y rechazo de ethnoi diferentes del propio, las reivindicaciones

1. La mencionada obra, escrita en 1984, no ha sido traducida al castellano; hemos consultado una edición italiana, cf. J. A. Brodskij, Marmi, Milano, 1995.

2. Como escribe el sociólogo Zygmunt Bauman en el célebre ensayo Strangers at Our Door, Cambridge 2016, los pueblos llamados 'barbaros' no eran necesariamente inferiores o menos humanos de los que así los definían. Eran simplemente diferentes. Pero ridiculizar, empequeñecer o ningunear a la alteridad desde siempre representó un fármaco efectivo, un mecanismo de defensa contra la presencia de pueblos o civilizaciones advertidos como amenazantes. 
identitarias de tipo defensivo o más frecuentemente agresivo han implicado para griegos y romanos una permanente confrontación con las exterae gentes ${ }^{3}$.

La autoconciencia de constituir la parte civilizada de la humanidad que se opone a un mundo inferior, atrasado, incivilizado, no ordenado, ha sido una constante a partir de las primeras manifestaciones literarias e historiográficas ${ }^{4}$, comportando la deformación en negativo de la imagen de los «otros» a través de la fijación de estereotipos y anécdotas de larga duración. Eso sin duda ocurrió también con los considerados barbaros por excelencia: los Hunos ${ }^{5}$. Cuando los guerreros esteparios aparecieron en las últimas décadas del siglo IV, lo que más miedo causó a los habitantes del Imperio fue la total ignorancia que se tenía de ese pueblo y de sus costumbres: un enemigo desconocido era más temible y peligroso que cualquier otro. Una vez identificado su lugar de origen con las estepas remotas de Asia continente implacable con espacios enormes y salvajes cuya naturaleza contagiaba, asimilán-

3. No acaso el estatus de extranjería irreducible del bárbaro, más allá de criterios de pertenencia étnica, a menudo es puesto en conexión con el tema de las migraciones, voluntarias a veces, forzosas muchas otras, cf. el clásico A. Momigliano, Saggezza straniera. L'Ellenismo e le altre culture, Torino, 1980 (ed. orig. Cambridge, 1975).

4. F. Hartog, Le miroir d'Hérodote. Essai sur la représentation de l’autre, Paris, 1980; E. Hall, Inventing the Barbarian. Greek Self-Definition through Tragedy, Oxford, 1989; Id., Ethnic Identity in Greek Antiquity, Cambridge, 1997; F. Millar, "Ethnic Identities in the Roman Near East, A.D. 325-450. Language, Religion and Culture”, en G. W. Clarke (ed.), Identities in the Eastern Mediterranean in Antiquity, Sydney, $1998 ; \mathrm{H}$. Ahrweler, "Byzantine Concept of the Foreigner", en H. Ahrweler - A.Laiou (eds.), Studies on the Internal Diaspora of the Byzantine Empire, Washington, 1998, pp. 4-5; S. Mitchell, G. Greatrex, K. Adshead (eds.), Ethnicity and Culture in Late Antiquity, London, 2000; M. Mazza, "Identità etniche e culture locali sulla frontiera dell'Eufrate (II-IV sec. d.C.). Uno studio sui contatti culturali”, en Id., Cultura, guerra e diplomazia nella Tarda Antichità. Tre studi, Catania, 2005, 13-115; M. Rocco, "La percezione delle identità etniche barbariche tra antico e tardoantico", Rivista storica dell'antichità, 41, 2011, 235-268; F. Curta, "Ethnicity in the Steppe Lands of the Northern Black Sea Region during the early Byzantine Times", Archaeologia Bulgarica 23, 1, 2019, 33-70. Muy interesante es también F. Giudice, R. Panvini (eds.), "Il greco, il barbaro e la ceramica attica: Immaginario del diverso, processi di scambio e autorappresentazione degli indigeni”, en Atti del Convegno internazionale di studi, Roma, 2007.

5. E.A. Thompson, A History of Attila and the Huns, Oxford, 1948; G. Moravcsik, Byzantinoturcica. Die byzantinischen Quellen der Geschichte der Turkvölker, I, Berlin, 1958, 479-488; O. Maenchen-Helfen, The World of the Huns: Studies in their History and Culture, Berkeley, 1973; S. Bock, "Los Hunos", en Antigüedad y Cristianismo. Monografías históricas sobre la Antigüedad Tardía, 9, Murcia, 1992; W. Roberts, The Victory Secrets of Attila the Hun, Bantam Doubleday, 1994; B. István: Les huns: Le grand empire barbare d'Europe (IVe-Ve siècles), Paris, 2002; G. Zecchini, Attila, Palermo, 2007; M. Rouché, Attila, la violence nomade, Paris, 2009, (trad. it. Attila, Roma, 2010); P. Heather, Empires and Barbarians: the Fall of Rome and the Birth of Europe, Oxford-New York, 2010; Ch. Kelly, Attila and the Huns. Barbarian Terror and the Fall of Roman Empire, 2008; E. Bozoky, Attila et les Huns, Paris, 2012 (trad. it. Attila e gli Unni. Verità e leggende, Bologna, 2014); C. D. Gordon, The Age of Attila. Fifth Century Byzantium and the Barbarians, Ann Arbor (Michigan), 2013; H. J. Kim, The Huns, Rome and the Birth of Europe, Cambridge, 2013. Ch. Kelly, "Neither Conquest nor Settlement: Attila's Empire and Its Impact", en M. Maas (ed.), The Cambridge Companion to the Age of Attila (Cambridge Companions to the Ancient World), Cambridge, 2014, 193-208. 
dolos, a los hombres que la habitaban ${ }^{6}$ - el miedo creció exponencialmente. Se despertó de inmediato esa feroz retórica sólidamente enraizada en el álveo de la tradición historiográfica greco-romana y que los acontecimientos venideros en parte justificarán: los Ounniká ethne serán los que causarán la caída de la frontera danubiana y que, poniendo en fuga los pueblos que convivían en esos territorios -Vándalos, Suevos, y Burgundios -, los empujarán hacia Occidente, el Mediterráneo y Roma7.

La demonización de los Hunos quizás llegó a su ápice en el siglo VI cuando el historiador Jordanes en una página de sus Getica relató una oscura leyenda sobre su génesis: entre los Godos que se estaban desplazando desde los países Escandinavos hacia Crimea, había unas brujas a las que el rey ordenó abandonar en una tierra desolada donde se unieron con unos espíritus inmundos, moradores de esas inmensas planicies. Los primeros Hunos «vagaron por los pantanos: eran pocos, tétricos, semejantes a los hombres pero distinguibles de ellos por algo que se parecía al lenguaje humano ${ }^{8}$. Ese pueblo que tenía una lengua extraña no se sentía atraído por las ciudades como por ejemplo los germanos, cuya fascinación hacia «un organismo hecho de estatuas, de templos, de jardines, de habitaciones, de gradas, de jarrones, de capiteles, de espacios regulares y abiertos» será tan hermosamente imaginada y descrita por Borges en un célebre cuento del Aleph ${ }^{9}$. Tampoco les interesaban la cultura escrita, ni las leyes, ni la religión ${ }^{10}$. Marginalidad y lejanía los identificaban como los bárbaros por antonomasia, por lo tanto crueles y feroces en grado máximo como intentan demostrar las conoci-

6. F.J. Guzmán, "Ammianus adversus externas gentes: la geografía del Barbaricum en Amiano Marcelino", Espacio, Tiempo y Forma, Serie II, Historia Antigua, 12, 1999, 217: «El arquetipo del bárbaro, inherente a la más honda esencia de la civilización clásica, no se basó únicamente en distintivos físicos aberrantes o en una interminable lista de costumbres incivilizadas. Por encima de estos aspectos, y condicionando todo el conjunto, se hallaba el medio natural en el que vivía...». Del mismo autor, v. "El «relevo de la barbarie»: la evolución histórica de un fecundo arquetipo histórico", Veleia: Revista de Prehistoria, Historia Antigua, Arqueología y Filología Clásicas, 20, 2003, 331-340; Id, "Los Hunos: la gran invención de Amiano Marcelino", RSA 31, 2001, 115-145.

7. Como escribe U. Roberto, “I popoli delle steppe e lo spazio mediterraneo: Unni, Avari, Bulgari”, en U. Eco (ed.), Il Medioevo: Barbari, cristiani, musulmani, Milano, 2010, 65-66, es lícito leer el proceso migratorio de los pueblos germánicos durante el siglo $\mathrm{V}$ como una huida para sustraerse a los Hunos que se transforma en un poderoso ataque armado en contra del Imperio.

8. Jordanes, De origine actibusque Getarum, XXIV, 127-128.

9. J.L. Borges, "Historia del guerrero y de la cautiva”, en El Aleph, 1949: «A través de una oscura geografía de selvas y ciénagas, las guerras lo trajeron a Italia, desde las márgenes del Danubio y del Elba... Quizá le basta ver un solo arco, con una incomprensible inscripción en eternas letras romanas. Bruscamente lo ciega y lo renueva esa revelación, la Ciudad».

10. Para la marginalidad escogida para preservar una propia identidad cultural por parte de pueblos que no quisieron o no supieron 'enculturarse', prefiriendo permanecer diferentes, a veces refugiándose en esa diversidad, la estudiosa argentina Nilda Guglielmi, Medioevo degli ultimi. Emarginazione e marginalità nei secoli XI-XIV, Roma 2001, propone la etiqueta de alógenos (de allo-y -genos, gr. ả $\lambda \lambda$ oүعvńs). 
das descripciones de Amiano Marcelino (343-400) en pasajes que representan eficaces paradigmas historiográficos de recepción y uso de los topoi etnográfico-literarios antibárbaros ${ }^{11}$.

Obliterando la mayoría de las críticas amianeas en línea con los tópicos más habituales y por todos conocidos de la representación de la barbarie ${ }^{12}$, nos interesa sondear en una de las caras de la diversidad focalizando la atención de la historiografía en el espectro conceptual de la alimentación y de la mesa. En el pensamiento antropológico la comida, interpretable como necesidad orgánica, proyección simbólica de la distancia entre lo sagrado y lo humano, o expresión muy elocuente de las estratificaciones sociales ${ }^{13}$, tiene la función de individuar

11. Como observa con perspicacia F. J. Guzmán Armario, profundo conocedor de la obra de Amiano, ("El relevo de la barbarie...", op. cit. 337): «Su retrato en las Res Gestae, confuso y hasta cierto punto pergeñado a duras penas, nos presenta a un pueblo subhumano, bestial, con unas costumbres vesánicas y un comportamiento totalmente opuesto al de los romanos». En relación con la representación de los Hunos por parte de Amiano, v. también S. Bonanni, "Ammiano Marcellino e i barbari", Rivista di Cultura Classica e Medievale 23, 1981, 125-142; B. Luiselli, "Lidea romana dei barbari nelletà delle grandi invasioni germaniche", RomanoBarbarica 8, 1984-1985, 33-61; T.E.J. Wiedemann, "Between Men and Beasts", en I. S. Moxon, J. D. Smart. A. J. Woodman (eds.), Past perspectives: studies in Greek and Roman historical writing, Cambridge, 1986, 189-201; C. King, "The veracity of Ammianus Marcellinus' description of the Huns", AJAH 12, 1987, 77-95; F.J. Guzmán Armario, "Las externae gentes bajo los estandartes de Roma: asentamiento y reclutamiento barbaros en las Res Gestae de Amiano Marcelino", RomanoBarbarica 17, 2000-20002, 85-115.

12. De esos tópicos, abundantemente analizados, recordamos principalmente cuatro: la fisicidad espantosa; las costumbres habitacionales primitivas; la vestimenta ferina; la promiscuidad con los animales. A propósito del primero, según Amiano los guerreros esteparios tienen un aspecto tosco y bruto; su dimensión física, grosera y repugnante (como es lógico observar desde una mentalidad en la que la fisiognómica, tekne codificada en época clásica y luego refinada en la helenística, sigue condicionando la percepción de los otros) está cercana a la bestialidad: «Su ferocidad va más allá de todo lo imaginable, con la ayuda del hierro trazan profundas cicatrices en las mejillas de los recién nacidos a fin de destruir todo germen de bozo; de esta manera envejecen imberbes y sin gracia, semejantes a eunucos. Tienen el cuerpo rechoncho, los miembros robustos, la nuca grosera. Su anchura de espaldas los convierte en terroríficos. Se diría que nos son animales bípedos o esas figuras mal talladas, en forma de troncos, que guarnecen los parapetos de los puentes, Amiano Marcelino, Rerum Gestarum, 31, II. 3. Con respecto al segundo topos, las formas habitacionales y en las praxis funerarias, escribe Amiano: «No tienen lugar en que abrigarse...Las casas no son utilizadas entre ellos, como tampoco las tumbas...» (31, II. 4). A propósito del tercero, el historiador critica las vestimentas constituidas por pieles ferinas, una afrenta hacia aquella urbanitas que impone en los pueblos civilizados una indumentaria para estar en casa y otra para salir y mostrarse: «Se cubren de lienzo o de pieles de rata de los bosques, cosidas conjuntamente. No cuentan con un traje para el interior y otro para salir. Una vez que se han endosado su túnica de un color desvaído no se la quitan hasta que se cae de vieja» (31, II, 5). Amiano sigue describiendo la tosquedad, rudeza, bestialidad de los Hunos, subrayando a propósito de esta última la relación estrechísima mantenida con los caballos («Podría creérselos clavados sobre sus caballos... no echan pie a tierra ni para comer ni beber. Duermen inclinados sobre el magro cuello de su montura donde reposan a su gusto»). La intimidad con los animales es advertida como una promiscuidad profundamente primordial y por lo tanto ajena a cualquier sentido cívico.

13. De los alimentos y las múltiples estrategias con las que la cultura los ha dotado de significados complejos en su relación funcional con las estructuras sociales, económicas y ecológico-productivas de las diferentes sociedades históricas, hablan con propiedad E. Di Renzo, Strategie del cibo. Simboli, saperi, pratiche, 
y distinguir, mucho más eficazmente que otros aspectos, a las personas, señalizar su estatus social, marcar su nivel cultural y económico. Y estas perspectivas son conocidas y explotadas por historiadores como Amiano cuya mirada en cuanto a la «nourritures de l'altérité» ${ }^{14}$ es obviamente etnocéntrica:

Los hunos no cuecen ni sazonan sus alimentos; se nutren únicamente de raíces salvajes o de carne cruda del primer animal que encuentran a mano (también el yogur, la leche de yegua), recalentándola tan solo durante cierto tiempo en la grupa de su caballo, sosteniéndola entre sus piernas ${ }^{15}$.

La incapacidad y/o el rechazo a comer alimentos cocidos significaban para los historiadores clásicos una distancia insalvable con respecto a la civilización de la mesa propia de la politeia griega que, desde siempre, tenía como praxis ineludibles la cocción de los alimentos y su consumo comunitario. No olvidemos que C. Lévi-Strauss fijaba la dicotomía entre lo crudo y lo cocido como metáforas respectivas de lo salvaje y de lo civilizado representando lo cocido una transformación cultural de lo crudo, que encarna el estadio del primitivismo ${ }^{16}$. En esta relación el fuego obviamente representa un fundamental elemento de mediación entre hombre y naturaleza, responsable, como enseñan los mitos, de establecer una ecuación entre cocido y socializado ${ }^{17}$. Antropología al margen, en el rechazo hacia la ingesta de carne

Roma, 2005; F. Neresini, V. Rettore (eds.), Cibo, Cultura e identità, Milano, 2008; G. Rotolo, La funzione del cibo come strumento di relazione interculturale, Palermo, 2017; L. Meglio, Sociologia del cibo e dellalimentazione. Un'introduzione, Milano, 2017; R. Gounelle, A.L. Zwilling, Y. Lehmann (eds.), Religions et alimentation. Normes alimentaires, organisation sociale et représentations du monde, Turnhout, 2020. Todas las monografías mencionadas coinciden en afirmar que, si por un lado la comida es esencialmente alimento, sustento, necesidad, por el otro es cultura, super-estructura, pensamiento. Si en términos de puro alimento es lo que permite al hombre realizar procesos biológicos vitales, su representación en términos de "hecho gastronómico" es lo que le permite convertirse en elemento identidario.

14. Encontramos especialmente sugerente el artículo J. Bahloul, "Nourritures de l'altérité: le double language des Juifs algériens en France", Annales E.S.C. 38, 1983, 325-340. Interesantes también M. Dietler, "Rituals of commensality and the politics of state formation in the princely societies of early Iron Age Europe", en P. Ruby (ed.), Les princes de la Protohistoire et l'émergence de l'état, Roma, 1999, 135-152; M. Dietler, "Theorizing the feast. Rituals of consumption, commensal politics, and power in African contexts", en M. Dietler, B. Hayden (eds.), Feasts. Archaeological and Ethnographic perspectives on food, politics, and power, Washington, 2001, 65-114. V. además el reciente G. P. Viscardi, "Mangiatori di pane. Il cibo come marcatore dellidentità civica da Omero a Platone" en I. Baglioni, E. Santilli, A. Turchetti (eds.), Il cibo e il sacro. Tradizioni e simbologie, Roma 2020.

15. «...neque igni neque saporatis indigeant cibis sed radicibus herbarum agrestium et semicruda cuiusvis pecoris carne vescantur, quam inter femora sua equorumque terga subsertam fotu calefaciunt brevi».

16. C. Lévi-Strauss, Mitológicas 1, Lo crudo y lo cocido, Ciudad de Méjico, 1964.

17. Reproduzco las interesantes reflexiones de M.C. Giorda, "Mangiare per essere: il cibo come identità", en M.C. Giorda, S. Hejazi (eds.), Nutrire lanima. A tavola con le religioni, Cantalupa, 2015, 14: «Il complesso universo simbolico che lega i cibi all'effetto che hanno sul corpo (caldo e freddo, umido e secco) o alla modalità in cui vengono consumati (cotti o crudi) e infine al loro essere buoni e puri, o cattivi e impuri, è legata 
cruda (practicada por los Germanos de Tácito, los Escandinavos de Pablo Diácono o los Mauros de Procopio) tuvieron que influir, además de tabú de antigua ascendencia (puridad, impuridad, contaminación ${ }^{18}$ ) también los praecepta de algunas escuelas filosóficas - pitagorismo, neoplatonismo etc.- y de las corrientes ascéticas cristianas que condenaban en general el alimentarse de carne, censurando como contra naturam la homofágia. La comida no elaborada de los Hunos consistía en plantas y raíces salvajes directamente recolectadas de las que no sabemos nada (la arqueo-botánica no nos aporta indicios significativos ya que no aparece en las fuentes ningún fitónimo ${ }^{19}$ ), topos que la barbarie comparte con la askesis monástica en el desierto y que implica, según la mirada de la historiografía de matriz griego-romana, una clara separación con respecto a la esfera de la socialización ${ }^{20}$.

Otros muchos elementos relativos a la alimentación y a la comensalidad como indicadores de alteridad con respecto a los Hunos los encontramos en el relato de la expedición al campamento de Atila de una delegación constantinopolitana en la que participó el autor del reportaje, Prisco de Panion, relato objeto ya de muchos estudios, pero en ninguno de ellos, por cuanto nos resulta, se ha prestado una atención histórico-antropológica a la alimentación y al banquete como marcadores alógenos. Previamente es necesario contextualizar el viaje de la legatio imperial y dedicar nuestra atención al autor de un relato historiográfico que constituye un unicum dentro de su género.

Del rétor e historiador tracio Prisco de Panion «universally recognized as the standard autority for the events of the years in question $»^{21}$ quedan unos fragmentos de su obra perdida, conservados por otros autores: Juan, patriarca monofisita de Antioquía en los años centrales del siglo VII, cuya Istoría Kroniké es fundamental para restablecer la tradición del original prisquiano, y Eustacio de Epifania en su Epitome; las partes relativas a las embajadas de los romanos apud externas gentes, o de los legados extranjeros apud romanos nos las preservaron, a través de un selectivo copy-past, los excerptores al servicio de Constantino Porfirogénito (Excerpta de legationibus ${ }^{22}$. Lo que se conserva nos hace pensar que la obra constaba de

al fatto che l'alimentazione costituisce una cerniera tra natura e cultura. Essa è infatti umanamente universale, in quanto questione di vita e di morte, eppure è profondamente variabile, diversificata, arbitraria».

18. M. Douglas, Purity and Danger: An Analysis of Concepts of Pollution and Taboo, London, 1966.

19. Un marco muy genérico lo podemos encontrar en L. Castelletti, Lalimentazione nellalto medioevo. Il contributo dell'archeobotanica, Spoleto, 2016, 87-164.

20. S. Acerbi, "La naturaleza del monje: elementos de una geografía espiritual”, en S. Montero y M.C. Cardete (eds.), Usos y abusos del medio natural. Naturaleza y religión en el mundo clásico. Actas del V Seminario Hispano-Italiano de historia de las religiones, Madrid, 2010, 259-272. Cf. también P. Ghidini, C. Scarpi, La scelta vegetariana. Una breve storia tra Asia ed Europa, Milano, 2019.

21. PLRE II: Priscus 1. E.A. Thompson, The Huns, 222; B. Baldwin, Priscus of Panion, Byzantion 50 (1980) 18-61.

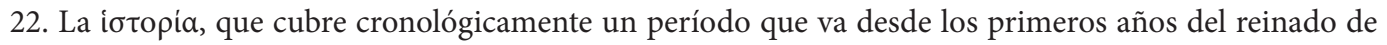
Teodosio II hasta la muerte de León I, la leemos a través de excerpta que se encuentran en otras fuentes de los siglos V-VI, hasta Constantino VII Porfirogénito (mitad de siglo X): Cf. las ediciones de C. Müller, Fragmenta Historicorum Graecorum, IV, Paris 1851, 69-110, V/1, Paris, 1870, 24-26 (= FHG), F. Bornmann, 
ocho libros y probablemente se dividía en dos partes: la Historia de Atila y la Historia de los Godos, que conjuntamente cubrían los años entre el 433 y el 471 . Ambas secciones eran fruto de las minuciosas anotaciones de Prisco en su diario personal y además de la documentación oficial procedente de la cancillería imperial a la que Prisco verisímilmente tenía libre acceso ${ }^{23}$.

Si Prisco, exponente significativo de la culta y pragmática clase administrativa constantinopolitana, y además testigo ocular de muchos de los acontecimientos que relata, fue apreciado por los autores que conservaron y trasmitieron su obra, esto se debe especialmente a su lucida mirada capaz, más allá de episodios específicos, de transmitirnos «la idea de una historia del Mediterráneo tardoantiguo como reflejo de una Ecúmene todavía unida tanto política como culturalmente $»^{24}$. Pero su fortuna también se atribuye a su incuestionable $v i s$ polémica hacia los últimos miembros de la dinastía teodosiana ${ }^{25}$. A pesar de ser funcionario

Fragmenta Prisci Panitae, Firenze, 1979; R.C. Blockley, The Fragmentary Classicising Historians of the Later Roman Empire: Eunapius, Olympiodorus, Priscus, vol. II, Liverpool, 1981, 222-376; P. Carolla, Priscus Panita, Excerpta et Fragmenta, Berlin, 2008; Los excerpta de legationibus (ELR: 167 fragmentos precedidos por un prólogo) fueron editados por primera vez por C. de Boor, Excerpta historica iussu imperatoris Constantini Porphyrogeniti confecta. Excerpta de legationibus, Berlin, 1903, 121-155, 575-591; P. Carolla, Excerpta historica iussu Constantini Porphyrogeniti confecta. Excerpta de legationibus Romanorum, Berlin-Boston (en prensa). El texto de Prisco, en relación a las fuentes que lo transmiten, ha sido estudiado por E. Doblhofer, Byzantinische Diplomaten und östliche Barbaren. Aus den Excerpta de legationibus des Konstantinos Porphyrogennetos ausgewählte Abschnitte des Priskos und Menander Protektor (Byzantinische Geschichtsschreiber 4), Graz, 1955; E.V. Maltese, "Note ed osservazioni sul testo di Prisco di Panium", Helikon 17, 1977, 297-320; Id., "A proposito dell'opera storica di Prisco di Panium", Quaderni di Storia 5, 9, 1979, 297-320; B. Baldwin, "Priscus of Panion", Byzantion 50, 1980, 18-61; U. Roberto, "Prisco e una fonte romana del V secolo", RomanoBarbarica 17, 2000-2002, 117-159; P. Carolla, "Priscus of Panion, John Malalas and the Chronicon Paschale: a Complex Relationship", en E. Juhász (ed.), Byzanz und das Abendland IV. Studia ByzantinoOccidentalia, Budapest, 2016.

23. El texto, muy extenso, del conocido como Frg. 8 según K. Müller, Fragmenta Historicorum Graecorum, Paris, 1941, 78-94, ha sido editado y traducido al inglés por R.C. Blockley, The Fragmentary Classicising Historians...op. cit. 222-376, esp. 246-287 (Müller, frg. 8 = Blockley, exc. 11,2; 12,1; 13,1; 13,3; 14; 15,1). Una buena traducción es la de J. Given, The Fragmentary History of Priscus. Attila, the Huns and the roman Empire (AD 430-476), Merchantville, New Jersey 2014.

24. Y además nos confirma que en Oriente existía un público muy interesado en la historia de Occidente: no es casual que su línea historiográfica fuese continuada por autores como Malco de Filadelfia o Cándido Isaúrico. Sobre "Prisco studioso dell'Occidente" y sobre el interés de la historiografía oriental hacia la Pars Occidentis cf. U. Roberto, Prisco e una fonte romana... op. cit., 119 n. 4. Cf. también R. Blockley, "The Development of Greek Historiography: Priscus, Malchus, Candidus", en G. Marasco (ed.), Greek and Roman Historiography in Late Antiquity. Fourth to Sixth Century A.D., Leiden, Boston, 2003, 289-315; W. Liebschuetz, "Pagan Historiography and the Decline of the Empire", en Idem (ed.), Greek and Roman Historiography ... op. cit., 177-218; W. Treadgold, The Early Byzantine Historians, Basingstoke, 2007; A. Milazzo, "Aspetti della storiografia tardoantica: Prisco di Panion", Mediterraneo antico 13, 2010, 99-112.

25. Suid. П 2301, I 2, pp. 694-695, Adler; cf. J. Harries, "Pius Princeps, Theodosius II and Fifth Century Constantinople", en P. Magdalino (ed.), New Constantines. The Rhythm of Imperial Renewal in Byzantium, ( $4^{\text {th }}-13^{\text {th }}$ Centuries), Belfast, 1994, 36; H. Elton, "Imperial Politics at the Court of Theodosius II", en A. Cain, 
en calidad de assessor, vinculado a Maximino ${ }^{26}$, un alto burócrata a servicio de Teodosio II, Prisco estaba próximo al entourage de Eufemio, que será el supervisor de la política intervencionista hacia los Hunos del sucesor del emperador, el general Marciano ${ }^{27}$.

En los años 441 y 443 Atila había llevado a cabo dos grandes incursiones en el Ilírico y en Grecia para forzar al Imperio a llegar a un pacto, y una embajada enviada por Teodosio II tuvo que negociar tales acuerdos ${ }^{28}$. Cuando los Hunos habían intensificado su presión en el limes del Imperio llegando casi hasta las puertas de la basileusa polis ${ }^{29}$ gravemente dañada

N. Lenski (eds.), The Power of religion in Late Antiquity, Farnham, 2009, 136-38. Prisco es el responsable de la imagen de Teodosio II como débil, fácilmente maleable, un títere afeminado e irresoluto en manos de mujeres y eunucos, heredada y sucesivamente difundida por autores posteriores, desde Evagrio en el siglo VI hasta Gibbon en el siglo XVIII: Teodosio «condemned to pass his perpetual infancy encompassed only by a servile train of woman and eunuchs», v. E. Gibbon, The History of the Decline and Fall of The Roman Empire, London, 1781, vol. III, 317. Una lectura muy seria y ecuánime del reinado de Teodosio II la encontramos en C. Giuffrida Manmana, Alla Corte dell'Imperatore. Autorità civili, militari ed ecclesiastiche nella Tarda Antichità, Catania, 2008, y Ead., Il potere e i suoi inganni, Nuovi modelli di comportamento nella Tarda Antichità, Roma, 2013.

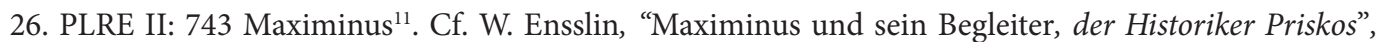
Byzantinisch-neugriechische Jahrbücher 5, 1926-1927, 1-9; E. Nechaeva, "Gli Sciti delle grandi migrazioni", en C. Ebanista- M. Rotili (eds.), La trasformazione del mondo romano e le grandi migrazioni. Nuovi popoli dall'Europa settentrionale e centro-orientale alle coste del Mediterraneo, Atti del Convegno internazionale di Studi, Cimitile 16-17 giugno 2011, Napoli, 2012, 20-31, sugiere identificarlo con Maximinus ${ }^{6}$ (PLRE II, 742) comes et magister scrinii memoriae; recientemente J. Given, The Fragmentary History of Priscus, op. cit. pp. xii-xiii, considera que, si Prisco era un assessor, trabajaba a servicio de Eufemio (Euphemius': PLRE II), no de Maximino. El autor (ibidem) duda incluso de que se tratara de un assessor: "It seems more likely that he followed Maximinos as an unofficial adviser".

27. E.A. Thompson, The Huns... op. cit., 215. Se trata de una imagen que no puede ser aceptada acríticamente: 6000 eran las libras de oro exigidas por Atila en el 443; esta suma era la que la clase senatoria tenía que aportar. Como ha calculado Thompson, si 2000 eran aproximadamente los miembros del ordo senatorial en la pars Orientis, la tasación no debía de superar los 60 centenaria de oro per-capita anuales, una cantidad a las que habrían podido enfrentarse sin caer en la ruina. Para la política de Marciano cf. R.L Hohlfelder, "Marcian's Gamble. A Reassessment of Eastern Imperial Policy toward Attila AD 450-453", American Journal of Ancient History 9, 1984, 54-69.

28. W.N. Bayless, "The Treaty with the Huns of 443", AJPh 97,1976, 176-179; G. Zecchini, "Prassi romana e prassi unna nelle reciproche relazioni politiche", en Mediterraneo Antico, 2, 1999, 777-791; C. Azzara, Le invasioni barbariche, Bologna, 2003: la táctica de los Hunos es definida por el historiador veneciano como "política del chantaje". Escribe G. Zecchini, "La politica dell'impero d'oriente nei Balcani dal 453 al 518", en U. Roberto, L. Mecella (eds.), Governare e riformare l'Impero al momento della sua divisione: Oriente, Occidente, Illirico, Roma, 2015: «Gli Unni privilegiarono sempre lo strumento diplomatico, solo sporadicamente affiancato dalla pressione militare, per ottenere migliori condizioni economiche (sussidi aurei; zone franche di mercato) e soprattutto una chiara linea di demarcazione tra due zone d'influenza: quella a sud del Danubio era riservata ai Romani, quella a nord era riservata agli Unni».

29. Como Prisco relata la ciudad fue defendida por el isaurico Zenón, que había relevado a Aspar, v. A.D. Lee, "Theodosius and His Generals", en C. Kelly (ed.), Theodosius II. Rethinking the Roman Empire in Late Antiquity, Cambridge-New York 2013, 90-108. 
por un seísmo en enero del 447, Prisco criticó duramente la estrategia adoptada por Teodosio II que, aconsejado por el fiel y todopoderoso ministro Crisafio ${ }^{30}$, había preferido no tomar las armas en contra del enemigo más insidioso del Imperio pactando al contrario su retirada con el pago de tributos anuales ${ }^{31}$. Si por un lado se evitaban de este modo los costes de nuevas campañas militares en la que las posibilidades de una victoria del ejército imperial habrían sido escasas, Teodosio II se veía obligado a tomar medidas fiscales en perjuicio de la clase senatorial constantinopolitana acostumbrada a privilegios e inmunidades y obligada a pagar, ya después del acuerdo con los Hunos firmado por el magister utriusque militiae Anatolio en el 443, un nuevo y humillante tributo ${ }^{32}$. Los que salían favorecidos eran los pequeños negotiatores y comerciantes que, sacando provecho de la apertura de las fronteras, animaban el sistema de los tráficos y de las comunicaciones, el emporikón ${ }^{33}$. A pesar de su postura crítica hacia la política de subsidios de Teodosio II, Prisco estuvo directamente implicado en las negociaciones realizadas en los años 448-449 y, junto con el amigo Maximino y el intérprete Vigilas, fue miembro de una misión diplomática que tenía que tratar temas de incumplimiento en la devolución de desertores y en el intercambio de prisioneros.

A finales del 448 había llegado a Constantinopla, acompañado por un tal Orestes - futuro magister militum en las Galias y padre del que será el último emperador de Occidente, Rómulo Augústulo-, entonces al servicio de Atila como secretario personal, un personaje de

30. PLRE II, 295: Chrisaphius.

31. Además de intentar mantener la paz, la línea adoptada preservaba de duros esfuerzos financieros a gran parte de la población que en el último decenio de la primera mitad del siglo $\mathrm{V}$ había sufrido a causa de terremotos, carestías y epidemias; Nestorio, Le livre de Héraclide de Damas, F. Nau (ed.), Paris, 1910, 318, describe la desesperada situación que se vivía en Oriente en los años de las dos grandes invasiones de Atila (441-443 e 447): «El pueblo había sido aniquilado por la peste y el hambre, por la falta de lluvias, después por el granizo, por el calor y por tremendos terremotos, por el terror y por todo tipo de males. Dos incursiones en la frontera de los bárbaros y de los Escitas estaban destruyendo todo y haciendo prisionero al pueblo que no tenía ninguna esperanza de rescate». Las duras condiciones dictadas por Atila a Teodosio II son relatadas en el fr. 3 de Prisco. El texto ha sido objeto de diferentes interpretaciones, cf. G. Wirth, "Attila und Byzanz. Zur Deutung einer fragwürdigen Priscusstelle", Bizantinische Zeitschrift 60, 1967, 54;

32. Como miembro de esa clase senatorial a los que fue endosado el alto precio de la paz, Prisco será quien se haga portavoz del descontento de su estamento social sucumbido a repentinos e injustos cambios de fortuna: los que habían detentado las riquezas durante mucho tiempo se habían encontrado en las plazas del mercado, después de haber vendido sus propios ajuares, para sacrificar también las joyas de sus mujeres. Esta calamidad, añadiéndose a las dificultades causadas por la guerra, había inducido a muchos al suicidio, Prisco, frg. 7. También el pasaje en que se relatan las tajantes peticiones de Atila suscita problemas de interpretación. Cf. G. Wirth, Attila und Byzanz..., op. cit., 47; E. V. Maltese, "Note ed osservazioni sul testo di Prisco...", op. cit. Se trata de una imagen seguramente amplificada por las claras simpatías políticas de Prisco, hostil a Teodosio II y muy en sintonía con la política intervencionista de su sucesor Marciano.

33. Para el favor de Teodosio II hacia las «non-aristocratic classes: craftsmen, merchants and manufacturers», cf. W.H.C. Frend, "The Monks and the End and the Survival of the East Roman Empire in the Fifth Century", Past and Present 54, 1972, 16. Resulta útil como marco de referencia P. Porena, "L'amministrazione tardoantica", en G. Traina (ed.), Storia d' Europa e del Mediterraneo, III, L'ecumene romana, VII, L'impero tardoantico, Roma, 2010, 525-600. 
alto rango, escita de estirpe, llamado Edeco, guarda de corps y amigo personal del rey huno. Fue introducido en la sala del trono, acompañado por Vigilas, el intérprete, pues Edeco no conocía ni el latín ni el griego mientras que a Orestes, que sí hablaba latín (lo que le resultó útil en las futuras misiones diplomáticas en Rávena), no se le permitió entrar. Después de haber tratado el tema de la restitución de prisioneros y desertores, recibió de parte del eunuco, que lo esperaba en un edificio cercano, la oferta de una ingente cantidad de dinero a cambio de la vida del rey huno ${ }^{34}$. Edeco aceptó la propuesta; sin embargo el complot contra Atila acabará frustrándose por su doble juego.

La delegación romana en la que participaban Prisco, el autor de reportaje y Maximino, después de un largo viaje de Constantinopla a Sárdica (donde había compartido un primer banquete con algunos hunos), había continuado hacia Naissus hasta las orillas septentrionales del Danubio, y luego, una vez atravesadas, mucho más lejos, en el corazón de la región que Prisco define Scitia ${ }^{35}$.

El fragmento 8, que narra las peripecias de este largo y accidentado viaje, está escrito en primera persona y de visu, por lo tanto constituye, como ha sido repetido en varias ocasiones, un documento de valor excepcional a partir del cual los historiadores antiguos y modernos han intentado reconstruir no sólo los hechos relativos a las relaciones entre Imperio y barbaros en el siglo V, sino también la personalidad de Atila y la vida cotidiana en los campamentos nómadas de su gente.

Aunque el relato de Prisco no exprese juicios psicológicos o morales sobre el rey huno, las características de su personalidad emergen incisivamente de los episodios que se relatan: no se trata de una estereotipada articulación de tópicos sobre la inferioridad bárbara sino de una observación atenta y bastante ecuánime, a pesar de una cuidada reelaboración literaria ${ }^{36}$. Michael Maas, uno de los muchos historiadores que han analizado el relato del «viaje de Prisco», también reconoce el papel del autor como «observador sagaz del complejo universo de las identidades en su tiempo, lejos de consideraciones del tracio como simplista y estereotipado» ${ }^{37}$.

La expedición constantinopolitana había llegado cerca del campamento de Atila a través de paisajes y encuentros cuya narración etno-geográfica ofrece momentos de sumo interés, cuando aparecieron mensajeros hunos que instaron a los embajadores a volver a

34. Prisco, exc. 7, 5.

35. Es oportuno especificar que se trata de la definición de Jordanes, ciertamente basada en el texto de Prisco.

36. El gusto de Prisco hacia las florituras retóricas y las referencias textuales a historiadores como Heródoto, in primis, y también Tucídides es subrayada en el interesante trabajo de O. Dinarés Cabrerizo, "El viaje de Prisco de Panion: un ejemplo de experimentación con fuentes literarias”, en P. D. Conesa Navarro, J. J. Martínez García Celso, M. Sánchez Mondéjar, C. Molina Valero, L. García Carreras (eds.), Antigüedad in progress, Actas del I Congreso Internacional de Jóvenes Investigadores del Mundo Antiguo (CIJIMA I), Murcia 2014, 419-440, especialmente 425-426.

37. M. Maas, "Fugitives and Ethnography in Priscus of Panium", Byzantine and Modern Greek Studies, 19, $1,1995,146-164,144$. 
Constantinopla. Prisco y Maximino quedaron sorprendidos por la actitud de los bárbaros y se prepararon para el regreso ${ }^{38}$. Sin embargo, un segundo corresponsal les ordenó que se detuvieran para pasar allí la noche, trayendo un buey y pescado de río como ofrendas de bienvenida. Las conversaciones estaban paralizadas cuando los legados romanos, dispuestos a regresar sin haber concluido nada con respecto a la devolución de rehenes, obtuvieron por fin una entrevista con el rey. La delegación fue tratada inicialmente con hostilidad: el rey prohibió a los romanos comprar artículos de valor y rescatar prisioneros. Pero «en las aldeas se nos proporcionó generosamente comida: mijo en lugar de trigo, y aguamiel, como se le llama en la lengua materna, en lugar de vino. A los asistentes que nos seguían se les suministraba mijo y una bebida de cebada que los bárbaros llaman kamon». Los romaioi ofrecen por su parte regalos: «tres tazas de plata, pieles rojas, pimiento indio, frutas de palma, dulces y otros obsequios muy apreciados por los bárbaros, porque no es fácil para ellos conseguirlos ${ }^{\bigotimes}$. De este y de otros fragmentos vemos cómo las relaciones internacionales se desarrollaban mediante embajadas que estipulaban pactos ratificados o por el envío de otros legados o sellados gracias a dádivas ${ }^{39}$. No podemos no observar por parte de los Hunos la incorporación de las mismas reglas y conductas de los adversarios en las formas de negociación, muestra de una clara adaptabilidad cultural tanto en la utilización de los recursos económicos y en las estrategias de socialización como en la apropiación de los alimentos de los otros. De hecho, el medio diplomático se sirve sobre todo de la circulación e intercambio de productos comestibles. Se trata de aldeas hunas donde la comida es abundante: los nativos ofrecen hidromiel -llamada medos $^{40}$ en algunos pasajes - a los viajeros, y vino de cebada, es decir cerveza, bebidas consideradas distintivas de los barbaros, vistas sin extrañeza por los romanos de Oriente.

En las semanas siguientes Maximino y Prisco siguieron a Atila a lo largo de todo su reino y, al llegar a un pueblo donde se encontraba una de sus residencias, lo vieron por fin dispuesto a negociar ${ }^{41}$. Prisco describe la bienvenida que se les rindió: Atila se mostró abierto

38. La orden de volver puede explicarse por el hecho de que el soberano había sido advertido del complot urdido en su contra, mientras que tanto Prisco como Maximino lo ignoraban. E. James, Europe's Barbarians, AD 200-600, London-New York, 2009, 269, subraya «la condición mental de los embajadores, obligados a depender de un intérprete del que sospechaban, desorientados por las intrigas de la corte, forzados a esperar durante días antes de poder tener una reunión y a volver continuamente a las discusiones realizadas para tratar de comprender su verdadero significado».

39. M. Godelier, El enigma del don, Barcelona, 1998; M. Mauss, Essai sur le don. Forme et raison de léchange dans les sociétés arcaïques, Paris, 1925 (trad. esp. Ensayo sobre el don: forma y función del intercambio en las sociedades arcaicas, Buenos Aires-Madrid, 2009) recalca que el "gift-giving" es marca de distinción social: quien más dona es superior a quien más recibe; quizás por esto no aceptar regalos ostentosos denota dignidad y prudencia. Elocuente a este propósito el siguiente locus: «Atila había ordenado a toda la élite de su corte que mostrara su simpatía hacia Maximino con regalos, y todos - entre ellos Berichus - le habían enviado un caballo. Aceptando solo algunos de estos animales, Maximino devolvió el resto, deseoso de mostrar moderación en sus pretensiones. Berichus tomó de vuelta su caballo y no quiso seguir viajando o comiendo con nosotros» (exc. 8, 192-193).

40. H. Gelzer, "Médos bei Priskos", Byzantinische Zeitschrift 24/2, 1923-1924, 313-314.

41. E.A. Thompson, "The camp of Attila", Journal of Hellenic Studies 65, 1945, 112-115. 
al dialogo y, como gesto de buena voluntad, permitió la liberación, previo pago de un rescate de 500 nomísmata, de una rica matrona romana y de sus hijos ${ }^{42}$.

Alejándose de los estereotipos a través de los cuales la tradición historiográfica había hasta entonces hablado de los guerreros esteparios, durante el tiempo transcurrido siguiendo al basileus Prisco ofrece una descripción minuciosa que incluye aspectos hasta entonces inexplorados: se detiene por ejemplo sobre las relaciones parentales/familiares que había podido observar visitando la casa de Atila y de Kreka, su esposa y madre de sus tres hijos; resalta rasgos temperamentales del rey poniendo en evidencia un talante noble e incluso carismático (como cuando lo vio salir de una de sus habitaciones con un rostro severo y sentarse frente al umbral para administrar la justicia rodeado por el respeto y la admiración de su pueblo ${ }^{43}$ ); describe la benevolente cordialidad mostrada hacia la esposa de uno de sus hombres de confianza, aceptando para honrarla, a pesar de no bajarse de su caballo, la comida y bebida de bienvenida que ella le había ofrecido ${ }^{44}$.

Seguirán en los días siguientes unos banquetes: Prisco y Maximino son invitados en la casa del Kreka ${ }^{45}$, un día, y al siguiente Prisco alude a otro excelente convite en la residencia del rey en el que se sirvieron viandas exquisitas. Se desarrolla un complejo ritual libatorio: todos los Hunos se levantaron y en turno ofrecieron a los huéspedes una copa llena de vino y la retomaron después de haberlos besado y abrazado. Los platos eran generosos y espléndidamente preparados - manjares bastante más elaborados y apetecibles que la carne cruda calentada entre los muslos y la espalda del caballo (tal como relataba Amiano) o la leche fermentada de yegua - y fueron consumidos de forma civilizada. Cantidades generosas de carnes cocidas, que quizás incluyan la caza ${ }^{46}$, desfilan ante los ojos de los Romaioi que asisten casi con estupor a tanta abundancia y ostentación de viandas, vinos excelentes, tejidos refinados que cubren los triclinios, entretenimientos musicales y cómicos ${ }^{47}$, platos y cubertería de

42. Prisco, frg. 8. La mujer era originaria de un pueblo que surgía a orillas del Danubio llamado Ratiaria. Cf. V. Neri, "I prigionieri romani dei barbari nella società dell'Occidente tardoantico (IV-VI sec.)", en M.Vallejo Girvés, J. A. Bueno Delgado (eds.), Movilidad forzada entre la Antigüedad clásica y tardía, Alcalá de Henares, 2015, 75-90; N. Lensky, "Captivity among the Barbarians and Its Impact on the Fate of the Roman Empire", en M. Maas (ed.), The Cambridge Companion to the Age of Attila, Cambridge, 2015, $230-246$.

43. 8, 133-134.

44. «Cuando llegó a la casa de Onegesio, por el camino que lleva al palacio, la esposa de Onegesio salió con muchos sirvientes, algunos platos de carne y otros vinos, y (este es el mayor honor entre los escitas), lo saludó y le pidió que tomara la comida que había traído para él con cordial hospitalidad. Para complacer a la esposa de su amigo íntimo, comió sentado en su caballo, y los bárbaros que lo acompañaban le levantaron la bandeja de plata. Después de probar el vino que le fue ofrecido, fue hacia el palacio......». (Carolla ed., fr. 8, 88).

45. Exc. 8, 178

46. En un pasaje se dice que "Atila estaba ansioso de cruzar en territorio romano como en una cacería»; el símil, de gran concreción narrativa, confirma que la caza era una de las actividades desarrolladas por el pueblo nómada.

47. También en la corte bizantina el banquete es rodeado de músicas, cantos, bailes y actúa en él un bufón que hace reír a los invitados con su deformidad física y con sus actuaciones salaces. Cada vez que los can- 
oro y plata ${ }^{48}$. Sabemos que en época tardoantigua el uso de servicios de mesa de materiales preciosos era parte de las costumbres de las aristocracias y marcaba un limes entre mundo civilizado y mundo bárbaro ${ }^{49}$.

Sin duda la ocasión mejor para conocer las costumbres de los enemigos llegaría para la delegación constantinopolitana unos días después, en otro banquete con un mayor carácter de oficialidad con respecto a los anteriores a los que los embajadores habían sido invitados en una de las residencias de Atila. Como ya hemos observado, la alimentación es un instrumento de sociabilidad poderoso, además de un indicador de pertenencia que marca un limes muy definido entre identidad y alteridad culturales. «Regímenes alimentarios, normas de educación, utensilios de mesa o de higiene u otros rituales concernientes la comida tienen un sentido unificador para el grupo que los practica» ${ }^{50}$. En el mundo clásico la dimensión sociocomunicativa del acto toma el relevo («Nosotros» - dice un personaje de las plutarquianas Disputas Conviviales - «no nos invitamos a comer y beber simplemente, sino a comer y beber juntos $»^{51}$ ) y los valores simbólico-rituales adquieren preeminencia incluso respecto a la circunstancia por la que tiene lugar el convite ${ }^{52}$.

Configurándose como un acto colectivo, el banquete representa una asamblea donde el compartir la mesa y comida crea vínculos de consenso, además de una especie de ficticio parentesco que cementa las relaciones sociales horizontales; pero instaura también un vínculo vertical entre el anfitrión y los huéspedes. No sólo en el mundo civilizado sino también entre barbaros, el sentarse a la mesa con un personaje poderoso - un rey - era acordado «tras una meditada valoración de los huéspedes, y significaba privilegios que no se concedían de forma

tores (naukalioi) dejan de cantar las gestas del emperador, los comensales brindan a su salud en copas de metales preciosos adornadas de piedras duras (chalintzia).

48. Cf. el lienzo del pintor húngaro Mor Than titulado The Feast of Attila (1870), donde el rey está sentado mirando la opulencia de su corte: una imagen que no corresponde con el relato ofrecido por Prisco.

49. En algunos contextos geográficos la presencia de una cuchara de plata en las sepulturas se convertía en una marca de distinción social, v. I. Baldini, "Il tempo a tavola nel tesoro di argenterie di Classe", en I. Baldini y A. L. Morelli (eds.), Ornamenta, Tempo e preziosi. Tecniche di datazione per l'oreficeria tardoantica e medievale, Bologna, 2017, 171-192: «Forse questo stesso concetto è anche alla base del rituale transalpino di deporre nelle tombe un unico cucchiaio d'argento, a indicare l'appartenenza del defunto o della defunta a una élite che ha adottato uno stile di vita aristocratico secondo il modello romano-bizantino».

50. C. L. Strauss, Mitológicas III. El origen de las maneras de mesa, Madrid, 1970.

51. Plutarco, Disputas conviviales II, 10. El tema del convivio como exemplum civilitatis es un topos de larga tradición que desde el mundo clásico - Platón, Petronio, Luciano de Samosata - llega con fuerza y nuevos argumentos hasta el Humanismo y el Renacimiento que supieron hacer madurar la reflexión de los antiguos gracias a figuras como Erasmo de Rotterdam o León Batista Alberti.

52. Es significativo que en el siglo IV la costumbre de comer en soledad valiera a Juan Crisóstomo la acusación de misantropía. Los rivales político-eclesiásticos le reprochaban: «Come solo, sin recibir a ningún amigo como compañero de mesa». Poco le sirvió al obispo de Constantinopla replicar: «Esta es una acusación para simposiárcas, no para obispos», v. Martirio de Antioquía, Oratio Funebris, 73. Sobre la finalidad socializante del banquete v. A. Carile, "La funzione cerimoniale dei dittici eburnei a Bisanzio", Orpheus. Rivista di Umanità Classica e Cristiana 29/30, 2008-2009, 93-110. 
privada sino pública, para que todos fueran conscientes de sus implicaciones», conllevando para el anfitrión «no sólo el deber de escuchar al invitado, sino también de acceder a sus peticiones o prometer satisfacerlas» ${ }^{53}$. En el acceso a la mesa concurrían en suma obligaciones y expectativas de ambos lados.

Cuando volvimos a nuestra tienda, el padre de Orestes, Tátulo, vino y dijo: «Atila os invita a los dos a un banquete, y esto comenzará alrededor de la hora novena del día». Esperamos el momento oportuno, y cuando los que habíamos sido invitados a la fiesta y los embajadores de los romanos occidentales llegaron, nos detuvimos en el umbral delante de Atila. Los coperos nos ofrecieron una copa, según la costumbre local, para que pudiéramos orar antes de sentarnos. Cuando esto terminó, y probamos de la copa, fuimos a los lugares donde estaríamos sentados durante la cena.

Todas las sillas estaban alineadas a lo largo de las paredes de la casa a ambos lados. En frente estaba sentado Atila en un sofá, otro sofá fue colocado detrás de él, y luego se fue a su lecho, que estaba cubierta con sábanas blancas y bordados de colores como adorno, como las que usan los helenos y romanos para los que se casan. La posición de los que cenaban a la derecha de Atila se consideraba más honorable que la posición a la izquierda, donde estábamos a pesar de que Berichus - un noble entre los escitas ${ }^{54}$ - estuviera sentado delante de nosotros. Onegesio se sentó en una silla a la derecha del sofá del rey y, frente a Onegesio, dos de los hijos de Atila se sentaron en sus sillas. El hijo sentado en su sofá, no a su lado sino en la extremidad, miraba hacia abajo como en una señal de respeto a su padre.

Los barbaros muestran respeto hacia la consuetudo religiosa romana de acompañar la libación con un rezo y antes de ocupar los asientos que, previamente asignados, estaban dispuestos en un orden preciso ${ }^{55}$ según una estrategia diplomática muy meditada que recuerda la adoptada en las cortes imperiales; la cuidada disposición de las mesas y triclinios nos hace entrever una articulada estructuración social donde la asignación de los asientos tiene lugar

53. R. Teja, "Quid episcopi cum palatio? Cuando los obispos se sentaron en la mesa con Constantino", en G. Bonamente, N. Lenski y R. Lizzi Testa (eds.), Costantino prima e dopo Costantino, Bari, 2012, 209-224, especialmente 21 .

54. Para la traducción hemos consultado a Given, p. 72 (155); Bericho era un huno, cfr. Nechaeva, Gli Sciti delle grandi migrazioni,...op. cit., 84 y139. Sobre el término "escita" usado por Prisco tanto para los Godos como para los Hunos de Atila sin connotaciones etnológicas, v. Ead., Embassies-Negotiations-Gifts...op. cit., 29. Sobre Bericho, cf. Ł. Pigoński, "Berichus and the Evidence for Aspar's Political Power and Aims in the Last Years of Theodosius II's Reign", Studia Ceranea 8, 2018, 237-251.

55. Sabemos que en los banquetes de la corte oriental, celebrados en el Triklinium de los diecinueve lechos, en cada cama se ponían doce invitados, en estricto orden jerárquico, a la derecha y la izquierda de la mesa imperial. Las fuentes nos dicen que los invitados primero recitaban una plegaria y después vaciaban la copa a la salud del emperador (cf. infra, nota 61). 
según criterios jerárquicos ${ }^{56}$, expresión de un orden preciso donde el rango es ostentado en base a la proximidad al rey huno, y en el ritual de la copa ${ }^{57}$. El uso de los espacios, ponderado según la prosémica del poder que privilegia el clan familiar - el primogénito y tío están por delante del más anciano de los logades - sigue una lógica que nada tiene de irracional o de incívico. Derecha e izquierda son respetadas en su significado simbólico - según una polarización distintiva de la cultura occidental en sus matrices greco-romana y también hebraico-cristiana que favorece la primera sobre la segunda como en cualquier asamblea civil o religiosa del Imperio y de sus instituciones (por ejemplo los concilios) ${ }^{58}$.

En la ritualidad del banquete la praxis libatoria a la que son invitados los comensales extranjeros es realizada con extrema escrupulosidad: cuando cada huésped ha ocupado el sitio designado por el rey, el copero de Atila llena su copa, este hace un brindis a la salud del emperador, cede la copa al vecino que a su vez, levantándose, renueva el brindis, vaciando su copa para luego restituirla al copero ${ }^{59}$.

Cuando todo el mundo se había colocado de forma ordenada, un copero se acercó y le ofreció a Atila un poco de vino en una copa de madera. Lo tomó y saludó a los primeros de los invitados, y los que habían sido honrados por su saludo se pusieron de pie. No estaba bien que se sentaran hasta que el rey hubiera probado el vino o lo hubiera bebido y hubiera devuelto la copa al copero. Todos los presentes lo celebraron de la misma manera, una vez que Atila se sentó, tomando las copas y bebiendo después de un saludo. Cada invitado tenía su propio copero que debía

56. M. Montanari, Alimentazione e cultura nel Medioevo, Bari, 1988, 23 subraya el comer «secundum qualitatem personae». Véase también M. Fiano, "Il banchetto regio nelle fonti altomedioevali: tra scrittura ed interpretazione”, Mélanges de l'École Française de Rome, Roma, 2003, 637-682. Para otro contexto cultural: B. Effros, Creating Community with Food and Drink in Merovingian Gaul, New York, 2002. También en otras situaciones el orden jerárquico es respetado escrupulosamente: por ejemplo, cuando los jefes militares tienen que distribuirse los dones, exc. 8, 58: «Pero el hombre que había traído los regalos no los había distribuido a los reyes según el rango de cada uno. El resultado fue que Kouridachus, el mayor en el cargo, recibió los regalos en segundo lugar, y así, creyendo que había sido descuidado y privado de los honores adecuados, llamó a Atila contra sus camaradas».

57. A. Carile, "La prossemica del potere: spazi e distanze nei cerimoniali di corte", en Uomo e spazio nell'Alto Medioevo, Spoleto, 2003, 589-656; P. Cammarosano, "La prossimità al re presso i popoli germanici", en Potere e politica nell'età della famiglia teodosiana: i linguaggi dell’impero, le identità dei barbari, Bari, 2013, 395-455.

58. La palabra contiene en sí misma la raíz *dek-, común a dextera y a $\delta \varepsilon \xi$ ló (“derecho”), que hace referencia a la conformidad con la norma y al "recibir de manera apropiada", en clara alusión a la conservación de un protocolo ceremonial, como fuente primaria de orden en la socialidad... Tal polarización extremadamente lateralizada en la derecha es aún más fuerte en aquellas culturas que como las occidentales, se basan tanto en los fundamentos judeo-cristianos como en los greco-latinos: cf. P. Aretini, A destra e a sinistra. Lorientamento nel mondo classico, Pisa 1998, 21; v. también J. Ries, "L’ uomo religioso e il sacro alla luce del nuovo spirito antropologico", en E. Anati et alii (eds.), Trattato di antropologia del sacro, vol. I, Le Origini e il problema dell'homo religiosus, Milano, 1989, 35-58 (56).

59. No hemos podido consultar R. Bleichsteiner, "Zeremonielle Trinksitten und Raumordnung bei den turkomongolischen Nomaden”, Archivfür Völkerkunde 6/7, 1951/1952, 181-208. 
acercarse a cada comensal sólo cuando el copero de Atila se había retirado. Después de que el segundo hombre fuera honrado y seguidamente los otros en orden de jerarquía, Atila también nos recibió con el mismo ritual según el orden de los asientos. Cuando todos fueron honrados con su saludo, y los coperos salieron, se colocaron mesas para tres o cuatro o más hombres junto a la de Atila. De estos cada uno podía tomar la comida colocada en el plato sin dejar la disposición inicial de las sillas.

La praxis protocolaria, repetida por cada cambio de plato, demuestra la presencia de códigos del convivium bien definidos y formalizados que no dejan nada para la improvisación, y la perfecta adherencia a protocolos propios de la corte oriental ${ }^{60}$. Se trata, a nuestro modo de ver, de una imitatio imperii fruto de una asimilación voluntaria del ceremonial bizantino conocido seguramente gracias a los embajadores hunos que, junto con los intérpretes, eran invitados y recibidos en la corte, y se desarrolla exactamente como in prandio imperatoris ${ }^{61}$. Nos sorprende que en un interesante trabajo dedicado a los «Ritualiced encounters» y a las performances ceremoniales entre bizantinos y barbaros, aunque en una cronología posterior a la descrita por Prisco, Pohl hable de un «intricate seating order, which is also know from other sources about steppe peoples», cuando las similitudes con las costumbres convivales de la corte romana oriental son mucho más significativas de las que se han podido inferir, por la exigüidad de las fuentes, con las costumbre de otros pueblos nómadas.

Una vez que los coperos se fueron, otro asistente entró con un plato de carne ${ }^{62}$, seguido de otros artículos de comida como pan de mijo, un cereal de rápido crecimiento compatible con los cultivos de pueblos semi-sedentarizados ${ }^{63}$. Prisco había sido ubicado en asiento

60. La taxis (orden) en los xletòria (banquetes) imperiales será fijada en los Taktikà kletorològia y puesta en acto por los atriklines, v. I.I. Reiske (ed.), Constantino Porfirogenito, De Cerimoniis aulae Byzantinae, Bonn, 1829; A. Cameron, “The construction of the court ritual: The Byzantine Book of Ceremonies”, en D. Cannadine - S. Price (eds.), Rituals of Royality. Power and ceremonial in traditional societies, Cambridge, 1987, 106-136; N. Oikonomidès, Les listes de préséance byzantines des IXe et Xe siècles. Introduction, texte et commentaire (Le Monde Byzantin), CNRS, Paris, 1972 donde se describen y explican los banquetes de Navidad en el Palacio Imperial. Cf. también A. Carile, "Posto a tavola e gerarchia delle portate", en L'Alimentazione nell'Alto Medioevo. Pratiche, simboli, ideologie, Spoleto, 2016, 821-834.

61. Es de hecho la misma descrita en un episodio relatado por Sulpicio Severo en la Vita Martini, 23: el santo, huésped del emperador Magno Máximo, durante el banquete no devuelve la copa al emperador, tal como imponía el ceremonial, sino que la ofrece a su presbítero «existimans dignorem qui post se biberet», por suerte no suscitando el castigo sino la admiración del emperador.

62. «El sirviente de Atila fue el primero en entrar, trayendo un plato lleno de carne, luego los sirvientes que esperaban al fondo colocaron el pan y la comida en las mesas».

63. Una investigación llevada a cabo por miembros del Departamento de Arqueología de la Universidad de Cambridge (S.E. Hakenbeck, J. Evans, H. Chapman, E. Fóthi, "Practising Pastoralism in an Agricultural Environment: An isotopic Analysis of the Impact of the Hunnic incursions on Pannonian populations", PLoS ONE 12, 3, 2017) sobre restos óseos y dientes de esqueletos humanos hallados en sepulturas de diferentes localidades de Panonia que corresponden con la zona fronteriza del Imperio a mitad del siglo V, ha arrojado luz sobre cómo esas poblaciones pudieron haberse enfrentado a la llegada de los Hunos. El equipo analizó en los huesos las relaciones isotópicas de carbono, nitrógeno, estroncio y oxígeno, y estos datos 
bastante distante del rey, en la parte izquierda, pero había podido igualmente observar y registrar en su mente detalles significativos con respecto a la personalidad soberano (como la delicada atención dirigida al hijo menor, el favorito de Atila, al que un omen había anunciado que le sucedería en el trono).

Mientras a los demás invitados eran servidos víveres ricamente elaborados y colocados - more romano - en bandejas suntuosas, Atila había preferido alimentarse de una ración de carne, usando platos y una copa de madera (el kissybion de homérica memoria ${ }^{64}$ ). Prisco observa su comportamiento reservado y austero (el basileus no se une a la hilaridad suscitada en los invitados por la actuación de un bufón ${ }^{65}$ ), manifestando con su compostura unas sobriedad e impasibilidad soberanas que se reflejaban también en la vestimenta, limpia y esencial ${ }^{66}$. Recordemos que la metáfora del simposio ejemplifica algunos de los valores centrales en la cultura clásica - temperancia y modestia - y que, tanto en los códigos alimentarios, en la

fueron comparados tanto con restos óseos de sociedades agrícolas sedentarias de la Germania del siglo V como también con los de pastores nómadas de Siberia y Mongolia de la misma época, concluyendo que los rastros isotópicos en los esqueletos de las tumbas panónicas atestiguaban prácticas alimentares compatibles con un alto grado de movilidad de la población fronteriza, sugiriendo que granjeros instalados en el limes del Imperio dejaron sus casas para convertirse en nómadas dedicados al pastoreo como los Hunos, mientras que hubo también hombres y mujeres que de una vida errante pasaron a formas de existencia más estable. Al contrario de lo que la historiografía ha pensado hasta hace unas décadas, es decir que en las dos zonas existía un rígido control sobre las respectivas poblaciones, estas cambiaron de estilo de vida bi-direccionalmente a lo largo de su existencia; cambios que según investigadora principal del equipo, Susanne Hakenbeck, corresponden a los rápidos giros políticos y a la instabilidad de pactos y lealtades, a la vez que parecen demostrar cierto grado de cooperación y coexistencia entre los fronterizos. Se trataría de un intercambio, o alternancia de estrategias de subsistencia sin comparaciones en otros ámbitos territoriales. Lejos de experimentar un choque de culturas, como siempre se ha pensado, muchos habitantes en la zona del limes del Imperio se sintieron atraídos por el estilo de vida de los Hunos, al igual que algunos nómadas adoptaron estilos de vida más asentados. Los análisis bioquímicos dan a conocer los regímenes alimentarios de los unos y de los otros: la dieta de los agricultores consistía principalmente en la ingesta de trigo, verduras y legumbres, con un poco de carne y casi nada de pescado. La dieta de los barbaros errantes, por otro lado, era rica en proteínas animales incrementada por las del pescado. También comían grandes cantidades de mijo, planta muy resistente y de rápido crecimiento muy popular entre las poblaciones nómadas de Asia central que, gracias a su relación isotópica con el carbono muy distintiva, es fácilmente identificable en los huesos humanos analizados. El estudio británico y su enfoque metodológico han sido discutidos en Italia en un Congreso cuyas Actas se han publicado recientemente, v. C. Giostra (ed.), Migrazioni, clan, culture: archeologia, genetica e isotopi stabili. III Incontro per l'Archeologia barbarica, Mantova, 2019.

64. Hom., Od. 14, 78 y 16, 52. El pasaje de Prisco dice así: «De hecho, la comida refinada que se había preparado se servía en platos de plata, para los otros bárbaros y para nosotros, porque Atila no quería nada más que carne en una tabla de madera. Era temperante en todos los sentidos, ya que mientras se habían ofrecían copas de oro y plata a todos los hombres durante la fiesta, su copa era de madera», Carolla ed., frg. 8, 162, 45.

65. Carolla ed., frg. 8, 171, 47.

66. Exc. 13, 285 «Su vestimenta era muy sencilla y no se preocupaba de nada más que de la limpieza; ni la espada que llevaba a su lado, ni las hebillas de sus botas bárbaras, ni la brida de su caballo, estaban adornadas con oro o gemas como las de los otros escitas, ni con nada de gran valor». 
actitud en la mesa como la forma de vestirse y mostrar en público una conducta basada en el ejercicio de la moderación eran indicadores a través de los cuales la historiografía resaltaba, de manera directa, implícita o antifrástica, las cualidades y virtudes del buen soberano.

Prisco y Maximino, sentados más cerca del rey, pensaron que se les presentaba una estupenda posibilidad para concretizar un acuerdo, pero eso no sucedió. La expedición alcanzó sólo algunos de los resultados que se había fijado y se hicieron necesarias otras embajadas en el territorio enemigo.

\section{Conclusiones}

El diario de viaje de Prisco, escrito gracias a un privilegiado observatorio itinerante y a través de los datos de la experiencia directa, no parece doblegarse a las exigencias de un modelo antropológico romano-céntrico y, si se excluyen algunos episodios específicos ${ }^{67}$, se sustrae a la consueta retórica de la inferioridad bárbara presente en la historiografía greco-romana y bizantina.

Como ya ha sido observado, la descripción de las costumbres de los Hunos, una de las partes más originales del relato autóptico de Prisco, no expresa desprecio o sentido de superioridad, sino atención y, en algunos casos, sincera admiración ${ }^{68}$. La relación entre el Imperio Romano y el reino huno no parece haber sido concebida por el tracio en términos

67. Encontrándose en la residencia de Atila con un griego naturalizado, que elogiaba la libertad, la seguridad y la justicia disfrutadas bajo el mando huno, con la única condición de ser leal al soberano y saber llevar armas, comparándolas con la ineficacia, la tortuosidad y corrupción del gobierno imperial romano, Prisco responde exponiendo con habilidad retórica los principios en los que se basaba la constitución romana, pero luego parece estar de acuerdo con el interlocutor: aunque los principios eran valiosos, su aplicación era lamentable. La lucidez historiografica de Prisco y su sensibilidad antropologica le hacen capaz de transformar la alteridad en un observatorio privilegiado para evaluar la realidad política, no sin cierto sentido de autocritica. Por ejemplo, la aquiescencia del imperio a las presiones de Atila para Prisco es sin duda muestra de su debilidad (fr. 8, 94-114).

68. Admiración hacia las telas armoniosamente tejidas por las sirvientas de la corte, hacia la hospitalidad ofrecida por las princesas hunas a los embajadores romanos, hacia el hogar de Atila, construido en madera, pero con sentido común y buen gusto, y por lo tanto confortable. La residencia de Atila - construida en la desembocadura del Tisza (en la actual Hungría) con troncos de árboles y rodeada por una empalizada con torretas - era muy "moderna”; en un edificio de madera junto al del rey «vivía también su primer consejero, que había ordenado a un prisionero de Sirmio que le construyera un baño de piedra». La descripción más exhaustiva nos viene de Jordanes, Historia de los Godos 8, 34: «Después de cruzar grandes ríos, el Tisias y el Drica, llegamos al paraje donde en otro tiempo, Vidicula, el más grande de los godos, pereció por las emboscadas de los sármatas; y cerca de allí encontramos una aldea donde residía el rey Atila. Digo una aldea, pero semejante a una ciudad muy grande. Vimos allí un palacio de madera inmenso, construido con tablas pulidas y brillantes, cuyas uniones estaban tan bien disimuladas, que apenas podían descubrirse con mucha atención. Existían allí espaciosas salas para festines, pórticos de elegante arquitectura; y el patio del palacio, rodeado de alta empalizada, era tan grande, que su extensión sola bastaba para dar a conocer una mansión regia. Tal era el palacio de aquel Atila que mantenía bajo su dominación toda la barbarie, siendo dicha morada la que prefería a las ciudades conquistadas». 
de preminencia: con respecto a los esquemas de comportamiento de los 'otros', su descripción no insiste en los aspectos diferenciales y antitéticos más que en los analógicos, subrayando incluso algunas similitudes comportamentales, obviamente desde la aguda y orgullosa autoconciencia cultural intrínseca en la mentalidad romana, tanto oriental como occidental.

Por cuanto concierne la comida y la comensalidad, temáticas escogidas para estudiar la óptica de la alteridad en la obra historiográfica de Prisco, el frg. 8 representa una buena demonstración de cómo entre klinai y kýlikes, inter mensa et pocula, se escenificaba uno de los paradigmas más emblemáticos en base al cual griegos y romanos verificaban y medían su noción de civilitas. La alimentación aparece estructurada según reglas precisas pero dentro de un código cultural cuyo uso no parece asociado a una inmutable conciencia identidaria, sino abierto al exterior. Las costumbres alimenticias de los Hunos aparecen como el resultado de una fluida comunicación cultural que muestra la velocidad con la que los fenómenos de asimilación pueden repercutirse en arquetipos sociales tenaces como la comida. Tampoco en la praxis del convite la población huna aparece portadora de una estrategia distintiva de comportamientos en la cual pueda manifestarse la reivindicación de una especificidad de estirpe. Contactos diplomáticos e intercambios económicos en zonas de frontera parecen tener como efecto la asimilación por parte de los Hunos de los medios de subsistencia y también de los símbolos y rituales del poder, redefinidos en función de sus específicas connotaciones grupales. Estos hechos aparecen en línea con los resultados más recientes de la historiografía que se ocupa de la relación entre Romanos y Barbaros, que «ha ridimensionato l'assoluta alterità civile degli uni rispetto agli altri» ${ }^{69}$, comprobando un alto grado di liminaridad en los respectivos comportamientos socio-culturales ${ }^{70}$. Varios estudiosos subrayan la compenetración y evolución conjunta entre mundo romano y barbaricum que en siglo $\mathrm{V}$ ya no son realidades opuestas. Desde el siglo V los barbaros pertenecientes a las aristocracias de sus clanes han intuido la necesidad de convertirse en «realtà polietniche, fluide, aperte continuamente a nuovi influssi $»^{71}$. Lo que nos recuerda las palabras que Marguerite Yourcenar hace pronunciar a su Adriano al final de Las Memorias: «Si los bárbaros quieren apoderarse del imperio del mundo, se verán obligados a adoptar algunos de nuestros métodos, y terminarán por parecerse a nosotros».

La representación equilibrada, nada denigratoria de las relaciones políticas entre los dos pueblos puede ser el efecto de las condiciones en las que se llevó a cabo la expedición

69. Cf. S. Cosentino, "Guardando i barbari dalle rive del Bosforo", en Potere e politica nellétà della famiglia teodosiana (395-455), Bari, 2013, 125-139, 126, y la literatura científica allí citada.

70. R. Dubbini, M.P. Castiglioni, C. Mariateresa (eds.), Incontrarsi al Limite. Ibridazioni mediterranee nell'Italia preromana, Atti del Convegno Internazionale Ferrara 6-8 giugno 2019, Roma, 2020, dedicado a las fronteras en el mundo clásico y a la comprensión de los procesos de definición de los espacios socioeconómicos y culturales en la Antigüedad, en una perspectiva interpretativa que ve las zonas limítrofes como sistemas abiertos, de paso y por lo tanto de contacto y encuentro fluidos entre realidades diferentes.

71. S. Gasparri, “Tardoantico e alto Medioevo: metodologie di ricerca e modelli interpretativi”, en S. Carocci (ed.), Il Medioevo (secoli V-XV), VIII (Popoli, poteri, dinamiche), Roma, 2006, 27-61, W. Goffart, Barbarians and Romans, A.D. 418-584. The Techniques of Accommodation, Princeton, 1980. 
del 449: las perspectivas de acuerdo entre el Imperio Romano y el rey de los Hunos en ese momento eran todavía consistentes y la embajada de la que Prisco formaba parte tenía que consolidarlas $^{72}$. Sin embargo, el equilibrio político y militar fracasó en los años siguientes, cuando Atila lanzó una importante campaña militar contra el Imperio de Occidente, campaña que llevó a un extenso saqueo y destrucción en la Galia, y a la Batalla de los Campos Cataláunicos del 451 con la subsiguiente invasión del norte de Italia y la destrucción de Aquileia. Debido al estado fragmentario de la obra prisquiana, no sabemos si la exposición del cronista tomó diferentes tonos, acentuando la agresividad de los Hunos y añadiendo distancia entre esos mundos - los Romanos y los Otros - para nada concebidos y representados de forma radicalmente antitética ${ }^{73}$.

72. Cf. E.A. Thompson, “The Foreign Policies of Theodosius II and Marcian”, Hermatena 76, 1950, 74, C. Zuckerman, "L’empire d'Orient et les Huns. Notes sur Priscus”, Travaux et memoires 12, 1994, 159-182. Por otra parte, es admisible que el texto de Prisco muestre una actitud muy ecuánime entre Hunos y romanos para mostrar el enorme peligro que significaba Atila para el Imperio, especialmente durante el políticamente ineficaz (según Prisco) gobierno de Teodosio II.

73. Pero Crisafio, probablemente gracias a la intervención de Anatolio y de Nomo, que en 450 en una siguiente delegación llegaron al campamento de Atila cargados de oro (B. Croke, "Anatolius and Nomus: Envoys to Attila", BizantinoSlavica 42, 1981, 165-166) pudo salvar la vida, en contra de la postura del magister militum Zenón que estaba a favor de su inmediata destitución y ejecución Prisco, frg. 12 y 13 . Los historiadores modernos dudan de que Crisafio hubiese podido urdir por si solo un plan tan complejo. Piensan que el complot habría sido organizado por miembros del equipo de gobierno de Teodosio II que representaban la corriente contraria a la política conciliadora con los Hunos y que luego le endosaron la responsabilidad del fracaso para neutralizarlo, o incluso en la posibilidad que el mismo Teodosio conociera los hechos y hubiese participado en ellos. Prisco parece sugerir que el emperador, previamente informado de la trama, había dado su aprobación. Sorprende, en efecto, la rapidez con la que el complot fue descubierto y que Atila, ciertamente muy ávido, hubiese aceptado dinero y regalos renunciando a la cabeza del eunuco como si no creyera en su exclusiva responsabilidad. Es posible que Edeco y el intérprete Vigilas recibieran el encargo de otros con la orden de echar la culpa a Crisafio si eran descubiertos, o bien que todo el complot sólo fuera una refinada escenificación para hundir y neutralizar al eunuco y romper el acuerdo diplomático alcanzado por los negociadores de Teodosio. Efectivamente, la muerte de Atila no habría eliminado el peligro militar de los Hunos, al contrario, habría podido empujarles hacia la Capital beneficiando al partido favorable a la guerra. Aun así, después de que se desvelara el complot, las relaciones entre Atila y Teodosio en el último año de reinado de este último fueron muy conciliadoras, lo que empujó a Atila hacia el Occidente. Cf. la detallada reconstrucción de Ch. Kelly, Attila e la caduta di Roma, Milano, 2009, 176 sg. 